1812 OUTCOME OF CHILDHOOD SYSTEMIC LUPUS ERYTHEMATOSUS (SLE) WITH LUPUS NEPHRITIS (LN)

doi:10.1136/archdischild-2012-302724.1812

${ }^{1} \mathrm{M}$ llyas, ${ }^{1} \mathrm{~A}$ Salahuddin, ${ }^{2} \mathrm{RC}$ Butterfield, ${ }^{1} \mathrm{~A}$ Tolaymat. ${ }^{1}$ Pediatrics; ${ }^{2} \mathrm{Center}$ for Health Equity and Quality Research, University of Florida, Jacksonville, FL, USA

A total of 46 patients with SLE-LN were studied (91\% females; mean age 13.0 years; mean follow-up duration 5.9 years). Initial renal biopsy showed that out of 46 patients, 2 (4.3\%) had Class I, 14 (30.4\%) had Class II, 8 (17.4\%) had Class III, 20 (43.3\%) had Class IV and $2(4.3 \%)$ had Class V lupus nephritis. Based on the renal histopathology and clinical presentation, 23 (50\%) patients received intermittent intravenous cyclophosphamide bolus with prednisone and Azathioprine (AZT) or Mycophenolate Mofetil (MMF). The remaining $23(50 \%)$ patients were treated with corticosteroids alone or in combination with AZT or MMF.

Follow up renal biopsies were performed on 21 patients, 4 patients showed no change in histology, 8 patients showed histological improvement of lupus nephropathy, 9 patients showed progression of lupus nephropathy and 7 of these who progressed, were started on intermittent IV CYC bolus.

The clinical follow up revealed that out of 46 patients, $21.7 \%$ patients went into complete remission, $58.6 \%$ patients remained under control with immunosuppressant medications, 10.8\% patients had clinically active disease with normal renal function and $10.8 \%$ patients had adverse outcome. The adverse outcome included one patient developed chronic renal insufficiency, three (3) progressed to end stage renal diseases and one died. Five-year kidney survival was $93.5 \%$ and patient survival was $97.8 \%$.

Although IV CYC treatment has improved the mortality and morbidity in lupus nephritis but severe adverse effect makes it less than optimal for long term therapy.

\section{SERVICE PROVISION FOR CHILDREN WITH JUVENILE IDIOPATHIC ARTHRITIS (JIA) IN THE EAST OF ENGLAND (EOE); A COMPARION WITH NATIONAL CENTRES}

doi:10.1136/archdischild-2012-302724.1813

'PJ Bale, ${ }^{2} \mathrm{~K}$ Armon, ${ }^{3} \mathrm{~A}$ Kavirayana. ${ }^{1}$ Paediatric Department, Ipswich Hospital NHS Trust, Ipswich; '2Jenny Lind Children's Hospital, Norfolk and Norwich University Hospital, Norwich; ${ }^{3 P a e d i a t r i c ~ R h e u m a t o l o g y ~ D e p a r t m e n t, ~ B r i s t o l ~ R o y a l ~ H o s p i t a l ~ f o r ~ C h i l d r e n, ~}$ Bristol, UK

Introduction The EoE has no regional centre or clinical network for paediatric rheumatology. JIA has a prevalence of 1:100 (2), which suggests an estimated 1,200 cases managed in the 17 hospitals of the EoE. What sort of service do these children get, compared with agreed standards, and that provided by national and 'grid training' tertiary centres?

Aim To assess the service provision for children with JIA in the EoE against recommended standards of care as set out by ARMA/BSPAR 2010(1), and compare our results to national data.

Methods A questionnaire was sent to the Paediatric Rheumatology leads of the 17 hospitals in the EoE, focused on the service provision for paediatric rheumatology patients, against BSPAR/ARMA standards. Follow-up phone calls were made where necessary to ensure accuracy. Data from 15 National centres, including all 8 UK grid training centres were used for comparison (3).

Results 16 of 17 hospitals responded in the East of England.

Table 1. Shows the percentage of hospitals achieving each of the audited ARMA/BSPAR standards in EoE, compared with national centres, and grid training tertiary centres data alone. In summary, in grid tertiary centres 17 of 21 standards audited are achieved to a good standard (>85\%), whereas in the EoE only 3 .
Abstract 1813 Table 1

\begin{tabular}{|c|c|c|c|}
\hline Standard & $\operatorname{EOE}(n=16)$ & $\begin{array}{l}\text { National } \\
\text { centres }(n=15)\end{array}$ & $\begin{array}{l}\text { Grid Training } \\
(n=8)\end{array}$ \\
\hline $\begin{array}{l}\text { New patient appointment } \\
\geq 45 \text { min }\end{array}$ & 0.0 & 26.7 & 62.5 \\
\hline $\begin{array}{l}\text { Follow up appointment } \\
\geq 20 \mathrm{~min}\end{array}$ & 31.3 & 73.3 & 75 \\
\hline $\begin{array}{l}\text { Paed meum Nurse } \\
\text { specialist }\end{array}$ & 37.5 & 80.0 & 100 \\
\hline Paediatric Physiotherapist & 87.5 & 86.7 & 100 \\
\hline $\begin{array}{l}\text { Paediatric Occupational } \\
\text { therapist }\end{array}$ & 68.8 & 53.3 & 87.5 \\
\hline Access to Psychologist & 56.3 & 80.0 & 87.5 \\
\hline $\begin{array}{l}\text { Access to } \\
\text { Ophthalmologist }\end{array}$ & 100.0 & 100.0 & 100 \\
\hline Telephone helpline & 43.8 & 73.3 & 100 \\
\hline Paediatric Anaesthetic list & 50.0 & 73.3 & 100 \\
\hline Entonox available & 37.5 & 73.3 & 100 \\
\hline $\begin{array}{l}\text { Home Methotrexate } \\
\text { training }\end{array}$ & 56.3 & 68.7 & 87.5 \\
\hline Access to $M T X$ in $<4 / 52$ & 100.0 & 93.3 & 87.5 \\
\hline Prescribe biologics & 50.0 & 100.0 & 100 \\
\hline $\begin{array}{l}\text { Recruit to Biologics } \\
\text { registry }\end{array}$ & 50.0 & 73.3 & 100 \\
\hline Have audited biologic use & 25.0 & 46.7 & 75 \\
\hline Part of Clinical network & 6.3 & 80.0 & 87.5 \\
\hline Recruit to research & 25.0 & 60.0 & 87.5 \\
\hline $\begin{array}{l}\text { Involved in undergraduate } \\
\text { teaching }\end{array}$ & 75.0 & 73.3 & 87.5 \\
\hline Child friendly clinic setting & 81.3 & 93.3 & 100 \\
\hline Adolescent clinic & 18.8 & 53.3 & 75 \\
\hline $\begin{array}{l}\text { Referral to a specific aduit } \\
\text { rheumatologist }\end{array}$ & 75.0 & 93.3 & 87.5 \\
\hline
\end{tabular}

Conclusion The EoE hospitals fall seriously short in providing trained, specialist care for the estimated 1,200 children with JIA, suggesting serious inequality of access. Many standards are unachievable without commissioned resource. Our challenge is to improve provision within existing funding.

\section{References}

1. Arthritis and Musculoskeletal alliance (ARMA) Standards of Care for children and young people with Juvenile Idiopathic Arthritis 2010

2. Children's Chronic arthritis association website. HYPERLINK "http://www.ccaa.org.uk" http://www.ccaa.org.uk.

3. Dr Akhila Kavirayana (SpR Paediatric Reumatologist) personal communication of data presented at BSPAR Sept 2011, as yet unpublished.

\section{PSYCHOPATHOLOGICAL PROFILE AND HEALTH RELATED QUALITY OF LIFE IN NARCOLEPSY WITH CATAPLEXY ACROSS CHILDHOOD AND ADOLESCENCE: A CASE- CONTROL STUDY}

doi:10.1136/archdischild-2012-302724.1814

${ }^{1} \mathrm{E}$ Finotti, ${ }^{2} \mathrm{~F}$ Pizza, ${ }^{2} \mathrm{~F}$ Poli, ${ }^{2} \mathrm{C}$ Franceschini, ${ }^{30}$ Bruni, ${ }^{2} \mathrm{G}$ Plazzi. ${ }^{2}$ University of Bologna; ${ }^{2}$ Department of Neurology, University of Bologna, Bologna; ${ }^{3}$ Child Neuropsychiatry Unit, Sapienza University of Roma, Roma, Italy

Objectives The purpose of our study was to describe the behavioral aspects and quality of life of childhood narcolepsy with cataplexy (NC).

Methods We performed a case-control study based on self-administered questionnaires in $30 \mathrm{NC}$ hypocretin-deficient patients, 39 epilepsy patients, and 39 healthy controls matched for sex and age. Results Our population of children and adolescents with NC showed an increase in internalizing problems in line with previous reports, typically represented by withdrawal and depression symptoms, and somatic complaints. The two patients groups share higher scores than controls for anxiety disorders, attention, social and oppositional-defiant problems. Psychopathological profile in $\mathrm{NC}$ were found to be positively correlated with early NC onset, 